\title{
Ptosis repair: external levator advancement vs. Müller's muscle-conjunctiva resection - techniques and modifications
}

\author{
Jacquelyn F. Laplant ${ }^{1}$, Julia Y. Kang ${ }^{2}$, Kimberly P. Cockerham ${ }^{2,3}$ \\ 'Department of Ophthalmology, Tulane University School of Medicine, New Orleans, LA 70112, USA. \\ ${ }^{2}$ Central Valley Eye Medical Group, Stockton, CA 95207, USA. \\ ${ }^{3}$ Department of Ophthalmology, Byers Eye Institute, Stanford University, Palo Alto, CA 94303, USA.
}

Correspondence to: Dr. Kimberly P. Cockerham, Central Valley Eye Medical Group, 36 W Yokuts, Stockton, CA 95207, USA. E-mail: cockerhammd@gmail.com

How to cite this article: Laplant JF, Kang JY, Cockerham KP. Ptosis repair: external levator advancement vs. Müller's muscleconjunctiva resection - techniques and modifications. Plast Aesthet Res 2020;7:60.

http://dx.doi.org/10.20517/2347-9264.2020.69

Received: 6 Apr 2020 First Decision: 24 Aug 2020 Revised: 7 Sep 2020 Accepted: 21 Oct 2020 Published: 6 Nov 2020

Academic Editor: Raúl González-García Copy Editor: Cai-Hong Wang Production Editor: Jing Yu

\begin{abstract}
Surgical techniques for ptosis repair continue to evolve as we gain a better understanding of the anatomy and physiology of the eyelid. External repair by levator advancement and internal repair by Müller's muscleconjunctiva resection are the most established surgical techniques used for acquired ptosis today. Controversy over their relative indications, advantages, and disadvantages exist. The advent of new surgical techniques and modifications has further complicated traditional algorithms that guide a surgeon towards choosing an external vs. internal approach. Specifically, the use and interpretation of pre-operative phenylephrine testing has recently been challenged. The purpose of this study is to review the evolution of external and internal ptosis repair techniques, and current trends in pre-operative evaluation and surgical management of acquired ptosis.
\end{abstract}

Keywords: Blepharoptosis, ptosis, levator advancement, Müller's muscle-conjunctiva resection

\section{INTRODUCTION}

Blepharoptosis is one of the most commonly encountered eyelid disorders in ophthalmology. Management is primarily surgical; however, certain etiologies may improve with non-surgical management and

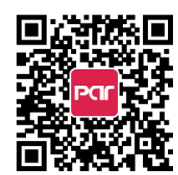



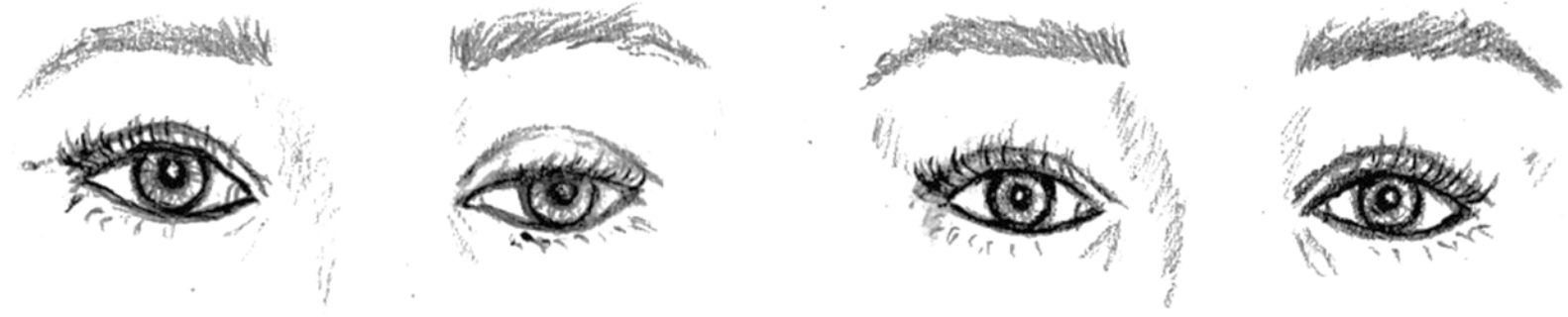

Figure 1. Before and after ptosis repair of left eye. Note the improvement in the MRD1 of the left eye post-operatively

treatment of underlying diseases. Surgical correction of ptosis has been performed for centuries with reports dating back to ancient Arabia and possibly ancient Rome ${ }^{[1,2]}$. Since then, hundreds of surgical techniques and modifications have been described [Figure 1].

Ptosis surgery generally falls into three categories: frontalis suspension techniques, external/transcutaneous repair of the levator complex, or internal/transconjunctival repair of the Müller's muscle, tarsus, conjunctiva, or levator complex. Accurate assessment of the etiology of ptosis is essential and can direct the surgeon to the most appropriate surgical options; however, there is significant variation in preoperative evaluation $^{[3-5]}$. In particular, the use of phenylephrine testing to identify suitable candidates for internal repair and to estimate postoperative outcomes has recently been revisited ${ }^{[6,7]}$.

The literature is replete with reports on advantages of different surgical techniques to treat similar etiologies ${ }^{[8-10]}$. This has led to further investigations on the anatomy of the levator muscle complex and Müller's muscle in an attempt to better define their roles in eyelid elevation and guide surgical interventions ${ }^{[11,12]}$. The most significant changes in ptosis repair techniques have resulted from a better understanding of the anatomy and physiology of the eyelid. In this review, we focus on the two most favored techniques that have emerged for surgical repair of involutional ptosis: the external levator advancement and the internal, Müller's muscle-conjunctiva resection (MMCR) and their modifications.

\section{EXTERNAL REPAIR TECHNIQUES}

The initial concept of aponeurotic repair was presented at a meeting held at the New York Eye and Ear Hospital in $1970^{[13]}$. Jones et al. ${ }^{[13]}$ were one of the first to describe the repair of involutional ptosis by addressing the levator aponeurosis. A detailed description of the anatomy of the levator anatomy was then provided by Anderson and Beard, emphasizing the importance of understanding the anatomy of the levator aponeurosis and its attachments to achieve desirable surgical outcomes ${ }^{[13,14]}$.

Histopathological studies performed during this time further demonstrated aponeurogenic defects with preservation of Müller's muscle, emphasizing that repair of this defect will address the underlying pathology to correct the ptosis ${ }^{[15]}$. Jones et al ${ }^{[13]}$ were one of the first to describe repair of the aponeurosis and Anderson and Dixon identified aponeuritic repair as the procedure of choice for acquired ptosis ${ }^{[16]}$. This led to the "Age of Aponeurotic Awareness" whereby external levator repair was recommended for all cases of ptosis with preserved levator function ${ }^{[17]}$.

Several techniques and modifications for levator aponeurosis repair have since been described ${ }^{[18-20]}$. Levator advancement and levator resection are among the most commonly performed external repairs used today. In levator aponeurosis surgery a transcutaneous incision is made at the lid crease and dissection through the orbicularis muscle is performed. While elevating the skin-orbicularis flaps the septum is identified through blunt dissection and opened to reveal the preaponeurotic fat and levator aponeurosis. After evaluating and mobilizing the levator aponeurosis the tarsal plate is exposed. If disinsertion has occurred, 
reattachment of the levator aponeurosis to the tarsal plate is performed or if the levator is stretched thin but still attached, a resection or advancement may be completed. This is often performed by placing a double armed 6-0 nylon suture on a spatulated needle partial thickness through the anterior surface of the tarsus corresponding to where the peak of the eyelid should be which is usually just nasal to the pupil. The length of the lamellar tarsal bite helps determine the eyelid contour. A shorter bite has an increased risk of peaking. The suture chosen varies and includes 6-0 silk, 6-0 vicryl, and 6-0 nylon, with either one central suture or a series of two or more sutures. Each needle is then passed through the levator aponeurosis and a temporary tie is placed. Intraoperative adjustments are performed as needed with the patient in sitting position to ensure desired eyelid height and contour prior to closure ${ }^{[21]}$. The patient's age and concurrent ocular co-morbidities should be taken into consideration when determining the optimal eyelid height. Younger patients may be able to tolerate small amounts of lagophthalmos, but older patients may be at risk for post-operative corneal exposure and exacerbate pre-existing ocular surface issues, especially if they have a poor Bell's reflex. The use of adjustable sutures that can be adjusted postoperatively has been described to help yield more predictable results ${ }^{[2,23]}$. A small incision technique has also been introduced and involves an 8 to $10 \mathrm{~mm}$ skin incision compared to the longer incisions used in conventional external ptosis repair $^{[24,25]}$.

The main advantages of external repair include suitability for all degrees of ptosis, the ability to make intraoperative adjustments, preservation of the conjunctiva, and direct visualization of important anatomical structures. An external approach can also allow for removal of excessive skin and fat if needed. Disadvantages of the external approach include a steeper learning curve, less predictability, increased risk of abnormal lid contour, and longer surgical times compared to internal approaches. Although a success rate of $70 \%-95 \%$ is reported in the literature, up to $20 \%$ require revisions with higher revision rates for bilateral ptosis repairs ${ }^{[2-28]}$. It has been suggested that change in lid height following local anesthesia could affect a surgeon's judgement of lid position intraoperatively due to the effect of epinephrine on Müller's muscle. In addition, some patients have extensive fat infiltration of the levator muscle making securing of shortening by resection or a tucking advancement of altered muscle more challenging ${ }^{[29,30]}$.

\section{INTERNAL REPAIR TECHNIQUES}

The principles of the posterior approach to ptosis repair is often attributed to Blascovic who described a posterior levator resection involving a tarsectomy in the early $1900 \mathrm{~s}^{[31]}$. In 1961, Fasanella and Servat described a modification of this technique that is now well-known as the Fasanella-Servat procedure for correction mild ptosis of $3 \mathrm{~mm}$ or less ${ }^{[32]}$. It was initially thought that this resection involved both the levator and Müller's muscles; however, histopathological analysis demonstrated no levator, indicating that it was a tarso-conjunctival and Müller's muscle resection ${ }^{[32]}$. In the same year that Jones et al. ${ }^{[13]}$ described the aponeuritic ptosis repair technique, Putterman et al. ${ }^{[33]}$ introduced the MMCR technique without levator resection or tarsectomy.

MMCR was originally described for patients with mild to moderate ptosis, good levator function, and a positive response to $10 \%$ phenylephrine testing ${ }^{[33]}$. Many mechanisms have been proposed for the success of MMCR including vertical shortening of the posterior lamella, Müller's muscle or levator aponeurosis plication or advancement, or induction of cicatricial changes ${ }^{[34]}$. Marcet et al. ${ }^{[35]}$ evaluated the histopathological changes of the eyelids in cadavers following MMCR and demonstrated that MMCR shortens the posterior lamella resulting in advancement of the levator palebrae superioris muscle and plication of the levator aponeurosis. Traditionally, an $8 \mathrm{~mm}$ resection was recommended to achieve the eyelid elevation observed on positive phenylephrine testing with appropriate modifications if the eyelid elevates higher or lower than desired ${ }^{[33]}$. Several algorithms have been developed in an attempt to better predict postoperative results ${ }^{[36]}$. Since its introduction, many modifications and new techniques have also been described, including the conjunctival sparing Müller's resection, isolated mullerectomy, 


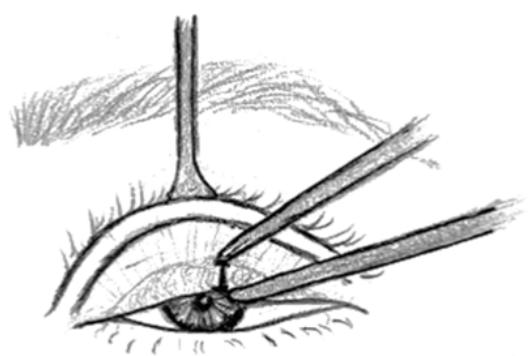

Figure 2. The upper eyelid is everted using a Desmares retractor and the desired resection is measured using calipers

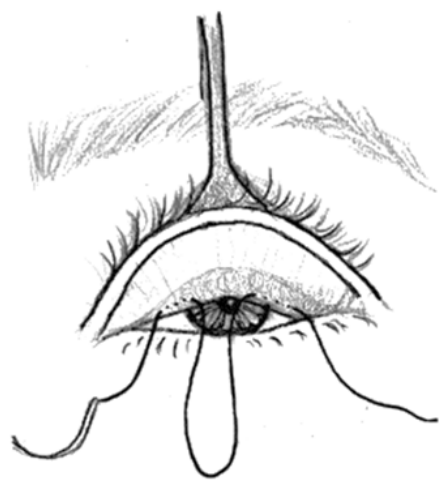

Figure 3. A 6-0 black silk suture is placed to mark the site
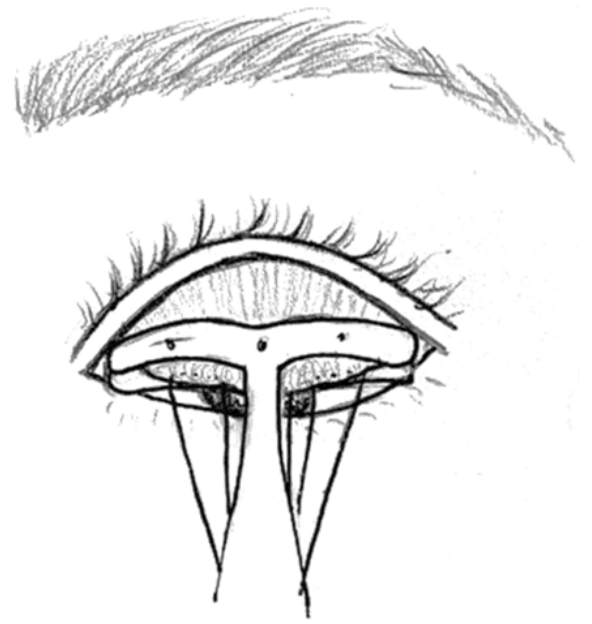

Figure 4. The 6-0 silk suture is tented up and the Putterman Muller's muscle-conjunctival resection clamp is placed

transconjunctival aponeurotic surgery without Müller's muscle resection, and transconjunctival levator plication $^{[37-41]}$.

\section{MMCR}

In traditional MMCR surgery a Desmares retractor is used to evert the lid and expose the posterior surface [Figure 2]. A predetermined amount of Müller's muscle and conjunctiva is measured and a marking suture is placed at this distance from the superior border of the upper tarsus [Figure 3]. A Putterman clamp (Bausch and Lomb, Storz, Manchester, MO) is placed containing the Müller's muscle and conjunctiva, and a running mattress suture is placed below the clamp in a temporal to nasal direction [Figures 4 and 5]. The tissue 


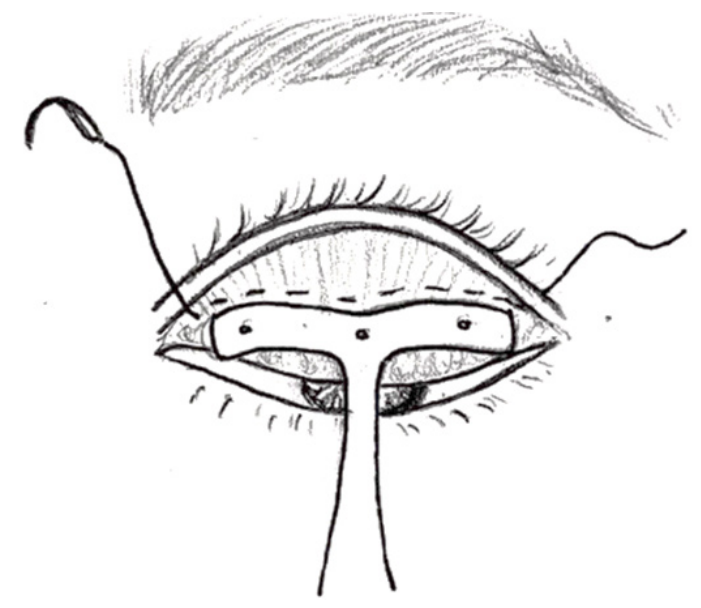

Figure 5. A 5-0 plain gut suture is placed approximately $1.5 \mathrm{~mm}$ below the Putterman clamp along its entire width in a temporal to nasal direction

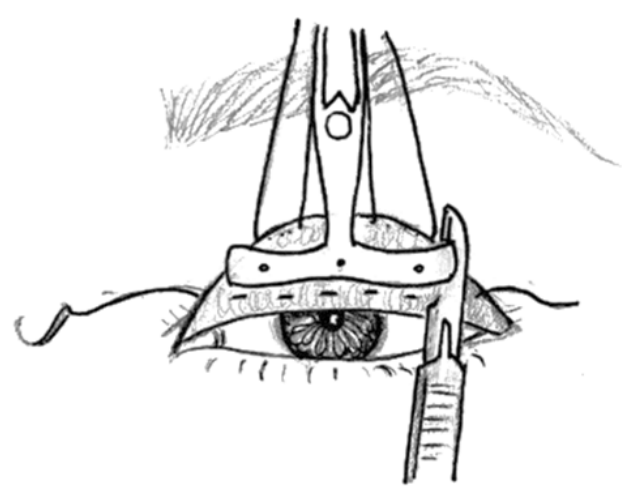

Figure 6. A \#15 surgical blade is used to excise the tissue by cutting between the suture and the clamp

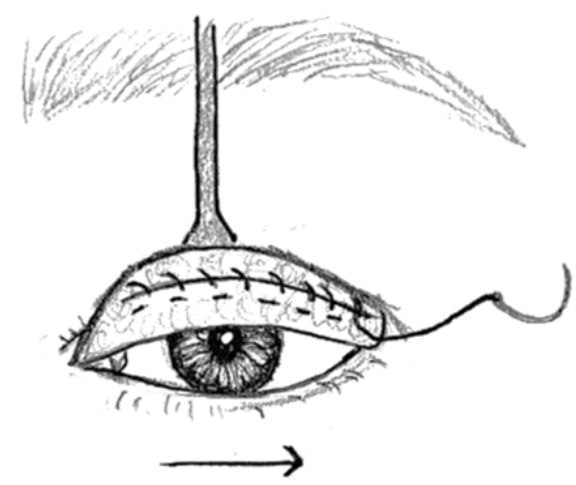

Figure 7. The suture is then passed in a running fashion from the nasal to temporal direction, burying the knot under the conjunctiva at the end

within the clamp is removed using a No. 15 blade avoiding the sutures [Figure 6]. The suture is then passed in a running fashion from nasal to temporal direction, burying the knot under the conjunctiva at the end [Figure 7]. Alternatively, the suture may be passed from the nasal to temporal direction with the clamp still attached and the excess conjunctiva and Muller's muscle removed with Wescott scissors [Figure 8]. Either single or double armed 6-0 or 5-0 plain gut sutures can be utilized. If using a single needle, the suture is passed through full thickness eyelid skin, run medially and then back laterally and externalized adjacent 


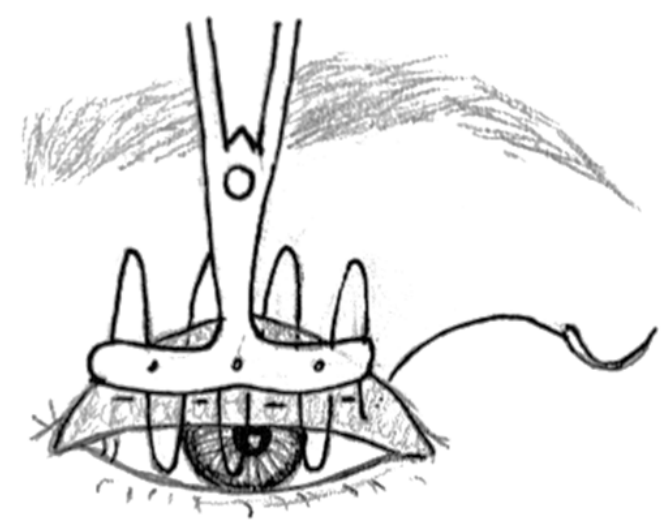

Figure 8. Alternatively, the suture can be passed from the nasal to temporal direction with the clamp still attached, and the tissue is excised with Westcott scissors
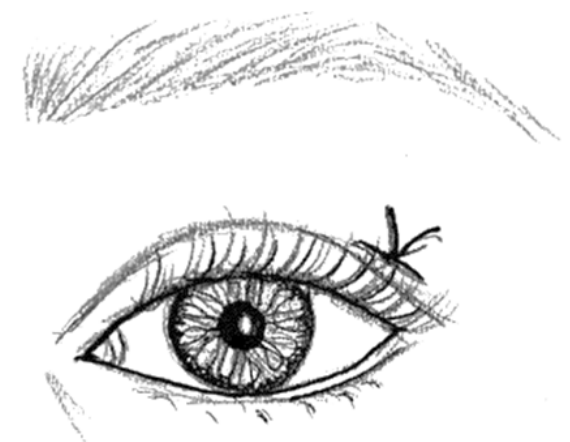

Figure 9. The suture can also begin externally with the knot externalized through the skin, or in a blepharoplasty incision if performing this procedure concurrently

to the entry track and tied off [Figure 9]. If double armed, both needles are passed full thickness through the eyelid and taped to the skin surface, and later removed. If combined with an upper lid blepharoplasty, the skin and fat removal is performed first and then a running suture is passed from medially then back laterally and the knot is tied on the surface of the orbicularis instead and then the skin is closed in standard fashion. Rarely, a Frost suture may be needed if there is not adequate eyelid closure to temporarily protect the ocular surface ${ }^{[21]}$.

Strengths of the MMCR technique are better predictability of postoperative outcomes, lower revision rates, preservation of lid contour, no intraoperative adjustment, faster recovery, and success in anophthalmic and high-risk patients ${ }^{[41,42]}$. Success rates of $80 \%-100 \%$ are reported in the literature for $\mathrm{MMCR}^{[33,43,44]}$. Weaknesses of MMCR include limited amount of elevation, variable resection algorithms, and irritation from posterior placed sutures. Early concerns for a reduction in tear production due to resection of conjunctival goblet cells and accessory lacrimal has not been shown to be clinically significant ${ }^{[45]}$. Classic teaching also advises not to perform an MMCR on a patient who has a negative phenylephrine test; however, this theory is being revisited ${ }^{[7,46,47]}$. Additional elevation can be achieved by performing a tarsectomy with the MMCR that results in the distance of the eyelash margin to clamp position of $5 \mathrm{~mm}$. Less than $5 \mathrm{~mm}$ of residual tarsus may increase the risk of upper eyelid entropion. A MMCR with tarsectomy has been performed in patients with moderate to severe ptosis and patients with a negative phenylephrine test with good levator function ${ }^{[48,49]}$. 


\section{Open sky technique}

Internal approaches can be further categorized into a "closed" technique utilizing a Putterman clamp and an "open sky" technique employing deeper surgical dissection ${ }^{[3,50]}$. In 2003, Lake et al. ${ }^{[51]}$ introduced a modification of Putterman's MMCR that allows for direct visualization of the Müller's muscle prior to resection with passage of sutures through the skin crease to advance the levator muscle to the tarsus. This is achieved by identifying Müller's muscle and removing its attachment to the levator aponeurosis, then passing a suture through the stump of Müller's muscle, underlying conjunctiva, and upper border of the tarsus exiting through the skin creas $\mathrm{e}^{[51]}$. A conjunctiva-sparing modification of this technique has also since been described ${ }^{[37]}$.

It is believed that this technique exerts its effect by effectively advancing the levator muscle through the stump of Müller's muscle and tarsus and/or by enhancing a stretch reflex transmitted to the levator muscle ${ }^{[51,52]}$. Success with the open sky technique has also been reported in patients with suboptimal levator function $^{[47,53]}$.

The main advantage of the open sky technique is the ability to adjust intra and post-operatively if overcorrected. This technique also does not require a clamp and avoids closure on the conjunctival surface, preventing irritation. Other strengths include direct visualization of Müller's muscle to allow for maximal resection, predictable outcomes, preservation of lid contour, and high success rate ${ }^{[47,51]}$. It may also be beneficial in patients with high aponeurosis defects and patients with negative phenylephrine testing ${ }^{[47]}$.

\section{UTILITY OF PHENYLEPHRINE TESTING}

The phenylephrine test is commonly used in preoperative assessment of ptosis; however, there is significant variation in how it is performed and interpreted. Putterman and Urist initially described phenylephrine testing as a means to identify candidates for the Fasanella-Servat and MMCR procedures ${ }^{[33]}$. They demonstrated a predictive role of phenylephrine testing for successful eyelid elevation after internal repair ${ }^{[3,54]}$. Phenylephrine testing is also used to identify subclinical contralateral ptosis whereby eyelid lowering is observed in the contralateral eyelid ${ }^{[55]}$. This is explained by Hering's law of equal innervation, whereby surgical repair of the ptotic eyelid results in decreased innervation to the bilateral levator palpebrae muscles, unmasking ptosis of a previously compensated contralateral eyelid. If contralateral ptosis is observed, phenylephrine drops are then administered to that eye and measurements are taken. A positive Hering's test may cause a surgeon to pursue bilateral ptosis repair to achieve better symmetry and avoid sequential surgery while other surgeons may defer surgery for the second eye $e^{[4,6]}$.

Traditional testing involves applying several drops of $10 \%$ phenylephrine to the superior conjunctival cul-de-sac to elicit eyelid elevation through the sympathetically innervated Müller's muscle. However, a concern for the adverse systemic effects of $10 \%$ phenylephrine, although short-lived, has caused many surgeons to adopt the use of $2.5 \%$ phenylephrine instead ${ }^{[56]}$. A study comparing $2.5 \%$ to $10 \%$ phenylephrine demonstrated a $0.2 \mathrm{~mm}$ higher elevation with $10 \%$ phenylephrine that was considered clinically insignificant ${ }^{[57]}$. Further, there is no consensus on the ideal time to wait before assessing for a response although eyelid height is commonly assessed after 5 to 10 min following instillation of phenylephrine ${ }^{[6,7,57-59]}$. It was recently reported that maximal response to phenylephrine occurs within 2 min of instillation and persists for $30 \mathrm{~min}$ in healthy subjects ${ }^{[60]}$. In contrast, another study identified a subset of patients who responded later than $10 \mathrm{~min}$ to $2.5 \%$ phenylephrine, drawing attention to the possibility of incorrect identification of such patients as "non-responders"

A positive phenylephrine test has traditionally been defined as elevation of the ptotic eyelid to a cosmetically acceptable level and has served as an indication for internal ptosis repair ${ }^{[33]}$. However, the classic teaching that an internal repair should not be performed in the setting of a negative phenylephrine 
test has recently been challenged ${ }^{[47,51,53]}$. Baldwin et al. ${ }^{[47]}$ demonstrated efficacy of MMCR performed in patients with ptosis and a negative phenylephrine test using an open-sky technique. Another study reported a direct correlation of a patient's response to phenylephrine with postoperative results but identified improvement of eyelid position in patients despite a suboptimal or negative phenylephrine test ${ }^{[46]}$.

The phenylephrine test is also utilized to reveal subclinical ptosis of the contralateral eye. The degree of eyelid elevation in phenylephrine testing has also been used to determine the amount of tissue to be resected in $\mathrm{MMCR}^{[33]}$. An $8 \mathrm{~mm} \mathrm{MMCR}$ is traditionally recommended to achieve the eyelid elevation observed on positive phenylephrine testing with a nomogram of $1 \mathrm{~mm}$ of lift achieved for every $4 \mathrm{~mm}$ of resection ${ }^{[33,61]}$. Several studies have since modified this formula; however significant controversy exists regarding its ability to predict postoperative outcomes with reports both confirming and negating the correlation between resection amount and post-operative results ${ }^{[36,62]}$. Further, Ben Simon et al. ${ }^{[7]}$ found that phenylephrine testing underestimated the degree of eyelid elevation achieved surgically by $40 \%$. Given the variability in phenylephrine testing, more studies are warranted to further characterize the responses in ptotic patients and its implications for surgical correction. The phenylephrine test is also useful to demonstrate the effect on the relative position of the eyelid height to the eyelid skin so that patients understand they may need an upper lid blepharoplasty either at the same time as the MMCR or subsequently.

\section{MÜLLER'S MUSCLE REVISITED}

Reports of good surgical results with internal ptosis repair in phenylephrine negative patients and achievement of eyelid elevation greater than $2 \mathrm{~mm}$ has led to the reconsideration of the role of Müller's muscle in eyelid elevation. It has long been taught that the levator aponeurosis functions as the main transmitter of the levator muscle while Müller's muscle primarily maintains the tone of the upper eyelid and contributes an additional $2 \mathrm{~mm}$ to lid elevation when sympathetically activated ${ }^{[63]}$. However, many argue that this alone does not account for the degree of ptosis observed in Horner's syndrome. Further, eyelid elevations ranging from 2.5 to $4.0 \mathrm{~mm}$ have been reported with MMCRs of 7 to $12 \mathrm{~mm}$ suggesting that the Müller's muscle may serve a larger role in eyelid elevation by transmitting the action for the levator muscle to the tarsal plate ${ }^{[11,12,36,64]}$. The authors routinely utilize this approach for patients with congenital ptosis, chronic progressive external ophthalmoplegia, third nerve palsies, and myasthenia gravis, independent of the phenylephrine response.

Another proposed role of Müller's muscle in the eyelid is by functioning as a muscle spindle, creating a continuous stretch reflex of the levator muscles. Matsuo et al. ${ }^{[52]}$ demonstrated that stretching of Müller's muscle resulted in involuntary tonic contraction of the ipsilateral or bilateral levator muscles, supporting that the Müller's muscle functions as a muscle spindle. Stretching and fatty infiltration of Müller's muscle with increasing age has also been observed on histopathological studies and could attenuate this reflex ${ }^{[29,65]}$. This could also account for the negative phenylephrine testing in some patients due to sympathetic denervation. Such fibro-fatty degeneration of Müller's muscle was recently observed on direct visualization on phenylephrine negative patients undergoing open sky $\mathrm{MMCR}^{[47]}$. Further, histopathological studies demonstrating a high concentration of alpha-2 receptors in Müller's muscle suggest that its response to phenylephrine may not represent its full role in eyelid retraction ${ }^{[66]}$.

Many attribute the success of MMCRs to incorporation of the levator muscle into the MMCR resulting in an "internal advancement" of the levator aponeurosis-müllerectomy conjunctival complex. Morris et al. ${ }^{[12]}$ confirmed the presence of levator muscle fibers on all histopathological specimens obtained from cadavers who underwent ptosis repair using a modified internal müllerectomy approach. It is likely that a combination of the above mechanisms contributes to the success of MMCR and that results vary by surgeon and the type of internal repair performed. 


\section{TRENDS IN CLINICAL PRACTICE}

The initial introduction of external and internal repair techniques created two diverging schools of thought that have persisted for decades. Many abandoned the internal repair techniques during the "age of aponeurotic awareness"; however, the internal approach has experienced a resurgence. In a recent survey sent to ASOPRS members, $100 \%$ and $74 \%$ of respondents perform external levator repair and internal repair techniques in their practice, respectively ${ }^{[5]}$. Respondents who were greater than 15 years out of fellowship were less likely to perform internal ptosis repair, suggesting that this choice could be associated with the repair techniques preferred at the time of their training. Interestingly, $84 \%$ of respondents indicated that they will perform internal repair on patients with moderate ptosis and $32.4 \%$ of respondents will perform internal repair on patients with severe ptosis. This differs from the classic practice of performing internal repair only in patients with mild to moderate ptosis.

A similar study was sent to British Oculoplastic Surgery Society (BOPSS) members to identify practice patterns. In contrast to ASOPRS members, $76 \%$ prefer external repair techniques as first line treatment of ptosis compared to $13 \%$ using a MMCR and $11 \%$ preferred an interior white-line levator advancement technique; however, the majority reported switching to a posterior approach in the setting of a positive phenylephrine test ${ }^{[4]}$. Interestingly, only $40 \%$ of BOPSS respondents regularly use phenylephrine for ptosis assessment compared to $59.9 \%$ of ASOPRS respondents. Over half of BOPSS respondents use phenylephrine testing to assess for subclinical contralateral ptosis, to determine surgical approach, and modify surgery based on observed eyelid elevation. The majority of both BOPSS and ASOPRS respondents utilize $2.5 \%$ phenylephrine rather than $10 \%$ phenylephrine to minimize the risk of cardiac effects.

Although most surgeons perform both external and internal repair, the debate over the favored technique for surgical repair of ptosis still exists. Both internal repair using MMCR and external repair through levator advancement demonstrate high success rates for ptosis repair and each is associated with its own strengths and weaknesses ${ }^{[8,67]}$. The only randomized controlled trial to date found that external levator advancement and MMCR were both effective in repair of mild to moderate ptosis; however, MMCR provided a better cosmetic outcome and less eyelid asymmetry ${ }^{[68]}$. In a retrospective comparison of 272 surgical procedures, Ben Simon et al. ${ }^{[8]}$ reported successful correction of involutional ptosis with both approaches although reported a higher reoperation rate in external repair (17\%) compared to internal repair $(<3 \%)$. A larger retrospective review of 1,519 patients also demonstrated higher revision rate in external repair $(9.5 \%)$ than internal repair $(6.8 \%)^{[69]}$. Another retrospective study instead compared small incision external repair and the Fasanella-Servat technique, demonstrating similar efficacy and patient satisfaction with both techniques, with lower operative times using the Fasanella-Servat technique ${ }^{[70]}$. To date, no studies have compared small incision external repair with MMCR.

\section{CONCLUSION}

The advancements in external and internal repair have added a myriad of techniques to the surgical armamentarium for correction of ptosis. Insights into the anatomy and physiology of the levator complex and Müller's muscle have helped us better understand the mechanisms employed by different surgical approaches although much remains to be elucidated regarding their contributions to eyelid elevation. Similarly, although phenylephrine testing maintains an important role in preoperative evaluation of ptosis, success with internal approaches in patients with phenylephrine negative testing suggests that a negative test does not necessarily predict a poor surgical outcome.

Despite changing attitudes towards external $v s$. internal repair and their indications over time, success has been achieved with both approaches. While internal approaches have consistently demonstrated lower revision rates and better cosmetic outcomes, external approaches are still preferred for more severe ptosis. 
Larger, randomized controlled studies with longer follow-up comparing the two approaches in mild to severe ptosis are needed to better identify which approach is preferred in certain situations.

\section{DECLARATIONS}

\section{Authors' contributions}

Conceptualization, writing, and editing of this manuscript: Laplant JF, Cockerham KP

Medical illustrations and editing of this manuscript: Kang JY

\section{Availability of data and materials}

Not applicable.

\section{Financial support and sponsorship}

None.

\section{Conflicts of interest}

All authors declared that there are no conflicts of interest.

\section{Ethical approval and consent to participate}

Not applicable.

\section{Consent for publication}

Not applicable.

\section{Copyright}

(c) The Author(s) 2020.

\section{REFERENCES}

1. Servat J, Mantilla M. The history of ptosis surgery. Adv Ophthalmic Plast Reconstr Surg 1986;5:133-7.

2. Beard C. History of ptosis surgery. Adv Ophthalmic Plast Reconstr Surg 1986;5:125-31.

3. Pereira IC, Matayoshi S. Quantitative comparison of the effect of 10\% phenylephrine instillation and manual elevation in patients with involutional blepharoptosis. Semin Ophthalmol 2017;32:172-6.

4. Mota PM, Norris JH. Review on surgical management of ptosis and the use of phenylephrine: a national survey of British Oculoplastic Surgery Society (BOPSS) UK Consultants. Orbit 2016;35:339-42.

5. Aakalu VK, Setabutr P. Current ptosis management: a national survey of ASOPRS members. Ophthalmic Plast Reconstr Surg 2011;27:270-6.

6. Barsegian A, Botwinick A, Reddy HS. The phenylephrine test revisited. Ophthalmic Plast Reconstr Surg 2018;34:151-4.

7. Ben Simon GJ, Lee S, Schwarcz RM, McCann JD, Goldberg RA. Muller's muscle-conjunctival resection for correction of upper eyelid ptosis: relationship between phenylephrine testing and the amount of tissue resected with final eyelid position. Arch Facial Plast Surg 2007;9:413-7.

8. Ben Simon GJ, Lee S, Schwarcz RM, McCann JD, Goldberg RA. External levator advancement vs Müller's muscle-conjunctival resection for correction of upper eyelid involutional ptosis. Am J Ophthalmol 2005;140:426-32.

9. Pang NK, Newsom RW, Oestreicher JH, Chung HT, Harvey JT. Fasanella-Servat procedure: indications, efficacy, and complications. Can J Ophthalmol 2008;43:84-8.

10. Park DH, Choi WS, Yoon SH, Shim JS. Comparison of levator resection and frontalis muscle transfer in the treatment of severe blepharoptosis. Ann Plast Surg 2007;59:388-92.

11. Bang YH, Park SH, Kim JH, Cho JH, Lee CJ, Roh TS. The role of Müller's muscle reconsidered. Plast Reconstr Surg 1998;101:1200-4.

12. Morris CL, Morris WR, Fleming JC. A histological analysis of the Müllerectomy: redefining its mechanism in ptosis repair. Plast Reconstr Surg 2011;127:2333-41.

13. Jones LT, Quickert MH, Wobig JL. The cure of ptosis by aponeurotic repair. Arch Ophthalmol 1975;93:629-34.

14. Anderson RL, Beard C. The levator aponeurosis. Attachments and their clinical significance. Arch Ophthalmol 1977;95:1437-41.

15. Dortzbach RK, Sutula FC. Involutional blepharoptosis. A histopathological study. Arch Ophthalmol 1980;98:2045-9.

16. Anderson RL, Dixon RS. Aponeurotic ptosis surgery. Arch Ophthalmol 1979;97:1123-8.

17. Anderson RL. Age of aponeurotic awareness. Ophthalmic Plast Reconstr Surg 1985;1:77-9. 
18. McCord CD, Seify H, Codner MA. Transblepharoplasty ptosis repair: three-step technique. Plast Reconstr Surg 2007;120:1037-44.

19. Scuderi N, Chiummariello S, De Gado F, Alfano C, Scuderi G, Recupero SM. Surgical correction of blepharoptosis using the levator aponeurosis-Müller's muscle complex readaptation technique: a 15-year experience. Plast Reconstr Surg 2008;121:71-8.

20. Singh D. Orbicularis plication for ptosis: a third alternative. Ann Ophthalmol (Skokie) 2006;38:185-93.

21. Black EH, Nesi FA, Gladstone G, Levine MR, Calvano CJ. Smith and Nesi's ophthalmic plastic and reconstructive surgery. 3rd ed. New York: Springer-Verlag New York; 2012.

22. Collin JR, O’Donnell BA. Adjustable sutures in eyelid surgery for ptosis and lid retraction. Br J Ophthalmol 1994;78:167-74.

23. Meltzer MA, Elahi E, Taupeka P, Flores E. A simplified technique of ptosis repair using a single adjustable suture. Ophthalmology 2001;108:1889-92.

24. Frueh BR, Musch DC, McDonald HM. Efficacy and efficiency of a small-incision, minimal dissection procedure versus a traditional approach for correcting aponeurotic ptosis. Ophthalmology 2004;111:2158-63.

25. Lucarelli MJ, Lemke BN. Small incision external levator repair: technique and early results. Am J Ophthalmol 1999;127:637-44.

26. Brown BZ. Ptosis revision. Int Ophthalmol Clin 1989;29:217-8.

27. McCulley TJ, Kersten RC, Kulwin DR, Feuer WJ. Outcome and influencing factors of external levator palpebrae superioris aponeurosis advancement for blepharoptosis. Ophthalmic Plast Reconstr Surg 2003;19:388-93.

28. Linberg JV, Vasquez RJ, Chao G. Aponeurotic ptosis repair under local anesthesia. Ophthalmology 1988;95:1046-52.

29. Cahill KV, Buerger GF Jr, Johnson BL. Ptosis associated with fatty infiltration of Müller's muscle and levator muscle. Ophthalmic Plast Reconstr Surg 1986;2:213-7.

30. Zhang L, Li B, Li L, Li Y, Zhang Y, Li DM. Pathological features of levator aponeurosis in patients with involutional blepharoptosis. Zhonghua Yan Ke Za Zhi 2018;54:671-7.

31. von Blaskovics L, Kreiker A. Eingriffe am Auge. 1st ed. Stuttgart: Enke; 1938.

32. Fasanella RM, Servat J. Levator resection for minimal ptosis: another simplified operation. Arch Ophthalmol 1961;65:493-6.

33. Putterman AM, Urist MJ. Müller muscle-conjunctiva resection. Technique for treatment of blepharoptosis. Arch Ophthalmol 1975;93:619-23.

34. Buckman G, Jakobiec FA, Hyde K, Lisman RD, Hornblass A, Harrison W. Success of the Fasanella-Servat operation independent of Müller's smooth muscle excision. Ophthalmology 1989;96:413-8.

35. Marcet MM, Setabutr P, Lemke BN, et al. Surgical microanatomy of the müller muscle-conjunctival resection ptosis procedure. Ophthalmic Plast Reconstr Surg 2010;26:360-4.

36. Dresner SC. Further modifications of the Müller's muscle-conjunctival resection procedure for blepharoptosis. Ophthalmic Plast Reconstr Surg 1991;7:114-22.

37. Khooshabeh R, Baldwin HC. Isolated Muller's muscle resection for the correction of blepharoptosis. Eye (Lond) 2008;22:267-72.

38. Ichinose A, Tahara S. Transconjunctival levator aponeurotic repair without resection of Müller's muscle. Aesthetic Plast Surg 2007;31:279-84

39. Singh D, Singh K, Singh SK, Singh RS. Sutureless levator plication by conjunctival route: a new technique. Compr Ther 2006;32:240-7.

40. Patel V, Salam A, Malhotra R. Posterior approach white line advancement ptosis repair: the evolving posterior approach to ptosis surgery. Br J Ophthalmol 2010;94:1513-8.

41. Saha K, Leatherbarrow B. Conjunctival sparing Müller's muscle resection for the management of blepharoptosis in the anophthalmic patient. Clin Exp Ophthalmol 2011;39:478-9.

42. Michels KS, Vagefi MR, Steele E, et al. Müller muscle-conjunctiva resection to correct ptosis in high-risk patients. Ophthalmic Plast Reconstr Surg 2007;23:363-6.

43. Carruth BP, Meyer DR. Simplified Müller's muscle-conjunctival resection internal ptosis repair. Ophthalmic Plast Reconstr Surg 2013;29:11-4.

44. Patel RM, Aakalu VK, Setabutr P, Putterman AM. Efficacy of Muller's muscle and conjunctiva resection with or without tarsectomy for the treatment of severe involutional blepharoptosis. Ophthalmic Plast Reconstr Surg 2017;33:273-8.

45. Dailey RA, Saulny SM, Sullivan SA. Müller muscle-conjunctival resection: effect on tear production. Ophthalmic Plast Reconstr Surg 2002;18:421-5.

46. Wee SW, Lee JK. Clinical outcomes of conjunctiva-Müller muscle resection: association with phenylephrine test-negative blepharoptosis and dry eye syndrome. J Craniofac Surg 2014;25:898-901.

47. Baldwin HC, Bhagey J, Khooshabeh R. Open sky Müller muscle-conjunctival resection in phenylephrine test-negative blepharoptosis patients. Ophthalmic Plast Reconstr Surg 2005;21:276-80.

48. Samimi DB, Erb MH, Lane CJ, Dresner SC. The modified fasanella-servat procedure: description and quantified analysis. Ophthalmic Plast Reconstr Surg 2013;29:30-4.

49. Perry JD, Kadakia A, Foster JA. A new algorithm for ptosis repair using conjunctival Müllerectomy with or without tarsectomy. Ophthalmic Plast Reconstr Surg 2002;18:426-9.

50. Werb A. Ptosis. Aust J Ophthalmol 1976; 4:40-3.

51. Lake S, Mohammad-Ali FH, Khooshabeh R. Open sky Müller's muscle-conjunctiva resection for ptosis surgery. Eye (Lond) 2003; 17:1008-12.

52. Matsuo K. Stretching of the Mueller muscle results in involuntary contraction of the levator muscle. Ophthalmic Plast Reconstr Surg 2002;18:5-10.

53. Cohen AJ, Weinberg DA. Müller's muscle-conjunctival resection for blepharoptosis with poor levator function. Ophthalmic Surg Lasers 
Imaging Retina 2002;33:491-2.

54. Shields M, Putterman A. Blepharoptosis correction. Curr Opin Otolaryngol Head Neck Surg 2003;11:261-6.

55. Gay AJ, Salmon ML, Windsor CE. Hering's law, the levators, and their relationship in disease states. Arch Ophthalmol 1967;77:157-60.

56. Stavert B, McGuinness MB, Harper CA, Guymer RH, Finger RP. Cardiovascular adverse effects of phenylephrine eyedrops: a systematic review and meta-analysis. JAMA Ophthalmol 2015;133:647-52.

57. Glatt HJ, Fett DR, Putterman AM. Comparison of $2.5 \%$ and $10 \%$ phenylephrine in the elevation of upper eyelids with ptosis. Ophthalmic Surg. Lasers Imaging Retina 1990;21:173-6.

58. Ayala E, Gálvez C, González-Candial M, Medel R. Predictability of conjunctival-Müellerectomy for blepharoptosis repair. Orbit 2007;26:217-21.

59. Putterman AM. Re: Phenylephrine test protocol. Ophthalmic Plast Reconstr Surg 2018;34:396.

60. Ramesh S, Mancini R. Dynamic analysis of Müller's muscle response to phenylephrine. Ophthalmic Plast Reconstr Surg 2016;32:46-8.

61. Putterman AM, Fett DR. Müller's muscle in the treatment of upper eyelid ptosis: a ten-year study. Ophthalmic Surg Lasers Imaging Retina 1986;17:354-60.

62. Weinstein GS, Buerger GF. Modifications of the Müller's muscle-conjunctival resection operation for blepharoptosis. Am J Ophthalmol 1982;93:647-51.

63. Carraway JH. Surgical anatomy of the eyelids. Clin Plast Surg 1987;14:693-701.

64. Kakizaki H, Malhotra R, Selva D. Upper eyelid anatomy: an update. Ann Plast Surg 2009;63:336-43.

65. Collin JRO, Beard C, Wood I. Experimental and clinical data on the insertion of the levator palpebrae superioris muscle. Am $J$ Ophthalmol 1978;85:792-801.

66. Esmaeli-Gutstein B, Hewlett BR, Pashby RC, Oestreicher J, Harvey JT. Distribution of adrenergic receptor subtypes in the retractor muscles of the upper eyelid. Ophthalmic Plast Reconstr Surg 1999;15:92-9.

67. Thomas GN, Chan J, Sundar G, Amrith S. Outcomes of levator advancement and Müller muscle-conjunctiva resection for the repair of upper eyelid ptosis. Orbit 2017;36:39-42.

68. Saonanon P, Sithanon S. External levator advancement versus Müller muscle-conjunctival resection for aponeurotic blepharoptosis: a randomized clinical trial. Plast Reconstr Surg 2018;141:213e-9.

69. Chou E, Liu J, Seaworth C, et al. Comparison of revision rates of anterior- and posterior-approach ptosis surgery: a retrospective review of 1519 Cases. Ophthalmic Plast Reconstr Surg 2018;34:246-53.

70. Sohrab MA, Lissner GS. Comparison of Fasanella-Servat and small-incision techniques for involutional ptosis repair. Ophthalmic Plast Reconstr Surg 2016;32:98-101. 